Systematic review

\title{
Effect of interactive media on the development of children and adolescents: systematic review with meta-analysis
}

\author{
Sabrina da Conceição Guedes ${ }^{1}$ (1) , Juliana Nogueira Pontes Nobre ${ }^{2}$ (i) , Rosane Luzia de Souza Morais ${ }^{2,3}$ (1) , \\ Rodrigo de Oliveira Mascarenhas ${ }^{3}$ (i) , Lívia Rodrigues Santos ${ }^{4}$ (D) , Vanessa de Oliveira Martins-Reis ${ }^{4}$ (i) , \\ Vinicius Cunha Oliveira ${ }^{1}$ (D) , Juliana Nunes Santos ${ }^{1,4}$ (i) \\ ${ }^{1}$ Universidade Federal dos Vales do Jequitinhonha e Mucuri, Programa de Pós-graduação em Reabilitação e \\ Desempenho Funcional, Diamantina, MG, Brasil; ${ }^{2}$ Universidade Federal dos Vales do Jequitinhonha e \\ Mucuri,Programa Saúde, Sociedade e Ambiente, Diamantina, MG, Brasil; ${ }^{3}$ Universidade Federal dos Vales do \\ Jequitinhonha e Mucuri, Departamento de Fisioterapia, Diamantina, MG, Brasil; ${ }^{4}$ Universidade Federal de \\ Minas Gerais, Programa de Pós-graduação em Ciências Fonoaudiológicas, Belo Horizonte, MG, Brasil.
}

Associate Editor: Ana Luiza Martimbianco, UNIMES/ Santos, SP, Brasil.

\begin{abstract}
Aim: to investigate through a systematic review of randomized controlled trials (RCTs) the effects of interactive media on the cognitive, language, and motor development of children and adolescents. Methods: Searches were performed with the Medline, AMED, Embase, PEDro, Cochrane, Psychinfo, and ERIC databases in May 2017 with updated in July 2020. For the search strategy, we used descriptors related to "randomized controlled trial", "interactive media" and "children and adolescents up to 18 years old". RCTs that investigated the effectiveness of interactive media in cognitive, motor, and language development of children and adolescents up to 18 years of age with typical development were included. When appropriate, meta-analyses were conducted using a random-effects model. Pooled data were presented using standardized mean difference and $95 \%$ confidence interval. We assessed the quality of evidence using the GRADE methodology and the methodological quality using the PEDro scale. Results: of the trials found, 14 references were eligible for this study. The GRADE methodology was used in 13 RCTs. Estimates showed a low level of evidence of a small effect of media use on cognitive development compared to that in the control group and another intervention. No effect on motor and language development. Conclusion: The results of this systematic review do not support claims about the advantages or disadvantages of interactive media in child development. High-quality evidence was found that interactive media is not superior to other interventions for cognitive and language development outcomes and quality of moderate evidence for motor and language development.
\end{abstract}

Keywords: child development; interactive tutorial; GRADE approach; systematic review; a meta-analysis.

\section{Introduction}

There is an increasing number of children and adolescents who use portable tablets, smartphones, and video games ${ }^{1,2}$. These devices are classified as interactive media, defined as multimedia systems that simultaneously integrate numerous audio and video elements that result in programs, games, animations, and graphics that promote interaction with the user, generating responses with visual and sound elements, with or without movement ${ }^{3}$. Linked to the increased use of these devices is a growing utilization of applications and software that improve specific skills for child development ${ }^{4}$, possibly influencing, and generating significant changes in the adolescence ${ }^{5}$. However, the rate of growth and the use of interactive media cannot be matched by scientific research, which leads to a lack of critical evaluation of the technology being used ${ }^{4,6}$. Some authors advocate the use of interactive media in educational settings to complement learning ${ }^{7-9}$, and students classify their experience with interactive media as positive, satisfactory, easy to use, and pleasant $t^{10-12}$.
Increased use of interactive media is mainly due to its portability, being lightweight, mobile, versatile, and intuitive $\mathrm{e}^{13,14}$. Their uses range from leisure and entertainment to communicate with distant relatives, to educational learning ${ }^{6,15-18}$. It is extremely important to note that the duration, mode, and activity performed when using interactive media determines its effect on the child and adolescent development ${ }^{1,19}$ since their brain is still under extensive changes in structure and function until the adolescence $\mathrm{e}^{5,20}$.

Considering the relationship between the interactive media and motor development, different outcomes are investigated: sedentary lifestyle time and physical activity level ${ }^{21-23}$ impact in gross motor skills ${ }^{24,25}$ and on fine motor skills ${ }^{26,27}$. Some studies affirm that there is an association between interactive media use and the sedentary lifestyle time in children and adolescents ${ }^{22}$, contributing to lower levels of physical activity ${ }^{23}$, negatively impacting the improvement of gross motor skills $\mathrm{s}^{21,22}$, in addition to a greater accumulation of body fat ${ }^{28,29}$. On the other hand, some studies verify if video games use can contribute to the 
improvement of motor skills related to control of objects ${ }^{24,25,30}$. Other studies have demonstrated a positive association between interactive media use and fine motor skills ${ }^{26,27,31}$.

However, considering the intrinsic relationship between the development domains is important to know the impact of interactive media, taking into account the cognition/language and socio-emotional domains of children and adolescents ${ }^{11,24,30}$.

The literature suggests and demonstrates that the adequate use of media is associated with a positive development cognitive $^{4,9,32}$, language ${ }^{7,33,34}$, and motor development in children ${ }^{24,25,26,30}$.

Additionally, the sensorial overstimulation from the use of interactive media can cause harm to the child and adolescent behavior $^{20}$ such as problems with self-regulation ${ }^{35}$ sleep disturbance $^{36}$ and language delay ${ }^{35}$. Since there is controversy within the literature, and there is a lack of consensus on whether interactive media use is beneficial or harmful, the need to review and clarify the subject is clear because interactive media is a potential intervention to be used not only in child and adolescents with typical development but also as a form of treatment for disabled people ${ }^{37}$. And nothing more advisable that the interventionist practices through the interactive media are based on evidence ${ }^{38}$. The alternative hypothesis of the present study was that interactive media is beneficial for the cognitive and language development of children and adolescents, and does not interfere with motor development.

The aim of this systematic review of randomized controlled trials (RCTs) was to investigate the effects of interactive media use on the cognitive, language, and motor development of children and adolescents.

\section{Methods}

\section{Search Strategy and Inclusion Criteria}

Search strategies were conducted to identify published RCTs investigating the effectiveness of interactive media in the development of children and adolescents of 2 to 18 years old since recent studies suggest that the brain development occurs up to adolescence ${ }^{20}$. Adolescence is a transition period between childhood and adulthood; the age range varies between cultures. In Brazil, adolescence is defined as up to 18 years, according to the Child and Adolescent Statute (ECA) ${ }^{39}$. This systematic review was prospectively registered in PROSPERO (CRD42019122367) https://www.crd.york.ac.uk/PROSPERO/ display_record.php?RecordID=122367. Medline, AMED, Embase, PEDro, Cochrane, Psychinfo, and ERIC databases were searched. The search strategy was conducted on May 5 th, 201,7, and updated on July 9th, 2020 without language and date restrictions. For search strategies, we used descriptors related to "randomized controlled trial," "interactive media," and "Children and adolescents up to 18 years old" (see Appendix 1 on the Addenda for detailed search strategy).

We considered "intervention with interactive media" those interventions that used devices such as tablets, smartphones, and video games, which promote interaction with the user, by emitting stationary or dynamic visual and acoustic signals. These media comprise a multimedia system that simultaneously integrates several elements of audio and video, and that results in programs, games, animations, and graphics ${ }^{3}$.

Published RCTs involving children and adolescents up to 18 years old were included. Although this age range is broad, it includes periods of great neurobiological maturation. In the preschool, period occurs a peak in the rate of brain development, that continues through the school-age and the adolescence ${ }^{20}$, when this population reaches and maturates important skills related to cognitive development, language, and socialization ${ }^{5}$. Any studies whose participants reported neurological disorders (such as cerebral palsy or syndromes that affect cognitive, linguistic, and motor aspects), autism, moderate-to-severe hearing loss, or mental or psychiatric disorders were excluded. The trials that were eligible for inclusion compared the effects of the use of interactive media on the development of children and adolescents (cognitive, language, and motor development) to control (no intervention, waiting list, placebo, sham, or other interventions (any other active intervention). The outcomes of interest were cognitive development (e.g., memory, math learning, colors), language development (e.g., new language learning, vocabulary retention), and motor development (e.g., object control skills, gross motor skills, fine motor skills).

\section{Study Selection}

Initially, the references identified were exported to an Endnote ${ }^{\circledR}$ file, and the duplicates were removed; then, two independent reviewers (SG and JPN) evaluated all titles and abstracts and selected potential full texts. The RCTs that matched the inclusion criteria were included in the review. A third reviewer (JNS) resolved the discrepancies $\mathrm{s}$ in 6 studies $^{40-45}$.

\section{Evaluation of Methodological Quality}

The methodological quality of the included trials was assessed using the 0-10 PEDro scale ${ }^{46}$. Two independent investigators (SG and JPN) evaluated each study, and a third investigator (JNS) resolved the discrepancies. When already available on PEDro, the values were extracted.

\section{Data Extraction}

Descriptive data from the included studies (i.e., participant characteristics, type of intervention, outcomes, and follow-ups) and results for all interest groups (sample sizes, means and standard deviations (SDs) were extracted by two independent investigators (SG and JPN), with discrepancies resolved by a third investigator (JNS). The results for the interest groups were extracted for short- and long-term effects. Short-term follow-up was defined as up to six months after initiation, and long-term follow-up was defined as more than six months after initiation. When more than one follow-up was performed, we evaluated the data from the earliest post-intervention report. 
Authors of five studies ${ }^{12,24,25,30,32}$ were contacted to clarify information not provided in the published article; we obtained a positive response from only one author ${ }^{24}$. Data from three studies for which we did not obtain a response $\mathrm{e}^{12,25,30,32}$ were imputed using Cochrane's recommendations ${ }^{47}$ for SD imputation of $\mathrm{p}$-value ${ }^{30}$; data from similar studies and the confidence interval (CI) of the difference between pre- and post-intervention ${ }^{25}$; and the standard error $(\mathrm{SE})^{32}$. Due to insufficient data, one study did not enter the quantitative analysis ${ }^{12}$.

\section{Data Analysis}

Where was possible, a meta-analysis was performed using a random-effects model ${ }^{48}$, in which the calculation of the weighting of each study is done using the inverse of variance methods. Meta-analysis was conducted using the random-effects model because the effects being estimated in the different studies are not identical. The model represents our lack of knowledge about why real or apparent intervention effects differ by considering the differences as if they were random. Heterogeneity between trials was identified, using $\mathrm{I}^{2}$ statistics $\left(\mathrm{I}^{2}\right.$ of $50 \%$ or more was considered moderate to high heterogeneity $)^{47}$. Estimates were presented using standardized mean differences (SMDs) and 95\% CIs in forest plots. When pooling was not possible, data from individual trials were reported. Effect sizes were interpreted according to Cohen's benchmarks: $d \geq 0.2$ for small; $d \geq 0.5$ for medium; and $\mathrm{d} \geq 0.8$ for large effects.

The GRADE system was used to summarize the evidence recommendations ${ }^{49}$. In the present review, the evidence began with high certainty. This was demoted one level for inaccuracy when the sample analyzed was $<400$ participants ${ }^{50}$; in one level for potential risk of bias when the mean PEDro score was $<5$ of 10 ; and in one level for inconsistency if $\mathrm{I}^{2} \geq 50 \%$ or if there was no meta-analysis. Investigation of publication bias was not possible due to the small number of studies included ${ }^{51}$. Two independent reviewers (SG and JS) evaluated the quality of the evidence, and discrepancies were resolved by a third reviewer (RM).

Sensitivity analysis was performed to investigate if the poor methodological quality of included trials impacted the overall estimates. As meta-regression was not possible because of the small number of included trials. Qualitative analysis to remove trials with poor methodological quality was conducted. We considered poor methodological quality trials scored $<5$ out of 10 on the $0-10$ PEDro scale. All analyses were performed using Comprehensive Meta-Analysis software, version 2.2.04 (Biostat, Englewood, NJ).

\section{Results}

\section{Characteristics of the Tests Included}

A total of 27,840 references were identified using the search strategy. After removing duplicates, the titles and abstracts of 19.457 studies were analyzed and 19.393 were excluded. The
64 potential complete studies were evaluated, and 50 were excluded. Exclusion criteria were: not being an RCT study $(n=17)$; not using interactive media in the intervention $(n=7)$; having children and adolescents with atypical development $(n=6)$; having people over 18 years old among the participants $(n=5)$; results not related to child development $(n=14)$, or not having a comparison of interest $(n=1)$. Fourteen original RCTs were eligible for this study $7,12,24,25,30,32,33,4552,53$. All of the trials evaluated only short-term effects. A flowchart of randomized clinical trials of this review is presented in Figure 1.

All fourteen studies were published in English, between 2015 and 2019. They included 1.966 children and adolescents, and the sample size ranged from $30^{12}$ to $603^{53}$ in individual studies (Table 1). Age ranged from 2 to 18 years; two studies did not report age ${ }^{11,12}$. Two studies ${ }^{12,33}$ did not report the sex of the participants; all the participants were females in one study ${ }^{10}$ and all the participants were males in another ${ }^{7}$. In mixed-sex studies ${ }^{8,9,11,24,25,30,32,45,52-54}, 51 \%$ of children and adolescents were male. The most evaluated

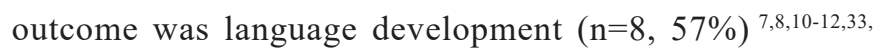
45,53 , followed by motor development $(n=3,21,4 \%)^{24,25,30}$ , and cognitive development $(n=3,21,4 \%)^{9,32,52}$. The trials selected for this review used various measuring instruments to analyze the outcomes. In all these instruments higher values indicate better performance. To assess motor development in object control skills, the Gross Motor Development Test-2 ${ }^{25,30}$ and Gross Motor Development Test-3 (TEMA-3) ${ }^{24}$ were used. The Grid tests ${ }^{32}$, the Early Mathematical Capacity Test- $3^{9}$, and the touch base evaluating working memory ${ }^{52}$ were used to assess cognitive development. For language development assessment The Validated Vocabulary Test ${ }^{10}$, Reading Proficiency Test ${ }^{11}$, Instant Vocabulary Posttests ${ }^{7,45,53}$, Reading Comprehension Scale ${ }^{12}$, Receptive Vocabulary Measure $^{33}$, and Print Concepts (such as direction, left and right discrimination, the concept of letters and words, and where to start reading) ${ }^{8}$.

Nine references used interactive tablet media ${ }^{8,9,11,12,32,33,45,52,53}$ and five used video games ${ }^{7,10,24,25,30}$. Of the studies included, six compared the use of interactive media with a non-intervention group $8,24,25,30,32,33$ and eleven with another intervention,

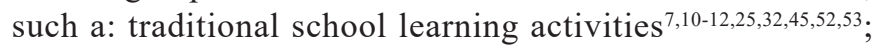
computer use in initial math activities or extra classroom activities similar to those performed in digital applications ${ }^{9}$; and observation of another child playing a video game ${ }^{7}$. With regard to duration, all were assessed in the short term.

\section{Methodological Quality of the Studies Included}

The methodological quality of the included studies ranged from 4 to 7 points on the 0-10 PEDro scale (median of 6) (Table 2). All studies reported random allocation and $93 \%$ $(n=13)$ scored equal to or greater than 5 points out of 10 on the PEDro scale. The main reasons for poor methodological quality were the lack of blinding of the participants $(n=14$, $100 \%)$, the therapist $(n=14,100 \%)$, and the evaluator $(n=11$, $78 \%)$, and absence of intention-to-treat analysis $(n=7,50 \%)$. 
Effect of Interactive Media on the Development of Children and Adolescents

\section{Motor development}

When compared to the group without intervention, the estimates showed a moderate level of evidence for no effect of video game use on short-term object-control skills acquisition ${ }^{24,25,30}$ $(\mathrm{n}=174)(\mathrm{SMD}=0.2,95 \% \mathrm{CI}-0.6$ to 1.0$)$. The GRADE rating was lowered due to inaccuracy.

When compared with another intervention (traditional method) the estimates showed a low level of evidence of no significant effect of video games on short-term ability to control objects ${ }^{25}$ $(\mathrm{n}=44)(\mathrm{SMD}=-0.3,95 \% \mathrm{CI}-0.9$ to 0.3$)$. The GRADE rating was lowered due to inaccuracy and inconsistency (single test).

\section{Cognitive development}

When compared to the control group (no intervention, waiting list, placebo, or SHAM), estimates showed a low level of evidence of a small effect of tablet use in solving mathematical problems and short-term memory work ${ }^{32}(\mathrm{n}=281)(\mathrm{SMD}=0.3$, 95\% CI 0.0 to 0.6 ). The GRADE rating was lowered due to inaccuracy and inconsistency (single test).

When the group using media was compared with another intervention (read an e-Book and extra classroom activities similar to those performed in digital applications), estimates showed little to no effect of tablet use on working memory and short-term number comprehension ${ }^{9,52}(\mathrm{SMD}=0.2,95 \% \mathrm{CI}-0.1$ to 0.5 ). The GRADE rating was high.

\section{Language development}

When compared to the control group (no intervention), estimates showed a moderate level of evidence of no significant effect of interactive e-book use on vocabulary retention ${ }^{33,53}$ and understanding of history ${ }^{45}$, and tablet and application use to improve short-term pre-literacy skills ${ }^{8,33}$ $(\mathrm{n}=725)(\mathrm{SMD}=0.6,95 \% \mathrm{CI}-0.1$ to 1.3$)$. The GRADE rating was lowered due to inconsistency.

When compared with other interventions (traditional method and observation), estimates showed a high level of evidence of no significant effect of the methods used playing video games ${ }^{7,10}$ reading an e-book together their book club ${ }^{53}$ and tablet activities ${ }^{11}$ on short-term vocabulary acquisition $^{7,10,11,53}$ and reading proficiency ${ }^{11}(\mathrm{n}=740)(\mathrm{SMD}=0.1$, $95 \%$ CI -0.3 to 0.6 ).

\section{Sensitivity Analysis}

Of all RCTs, only one clinical trial investigating the effect of interactive media on motor development compared to non-intervention presented a high risk of bias (PEDro score $<5)^{30}$ Sensitivity analysis for the risk of bias did not change the results of the meta-analysis presented in Figure 2.
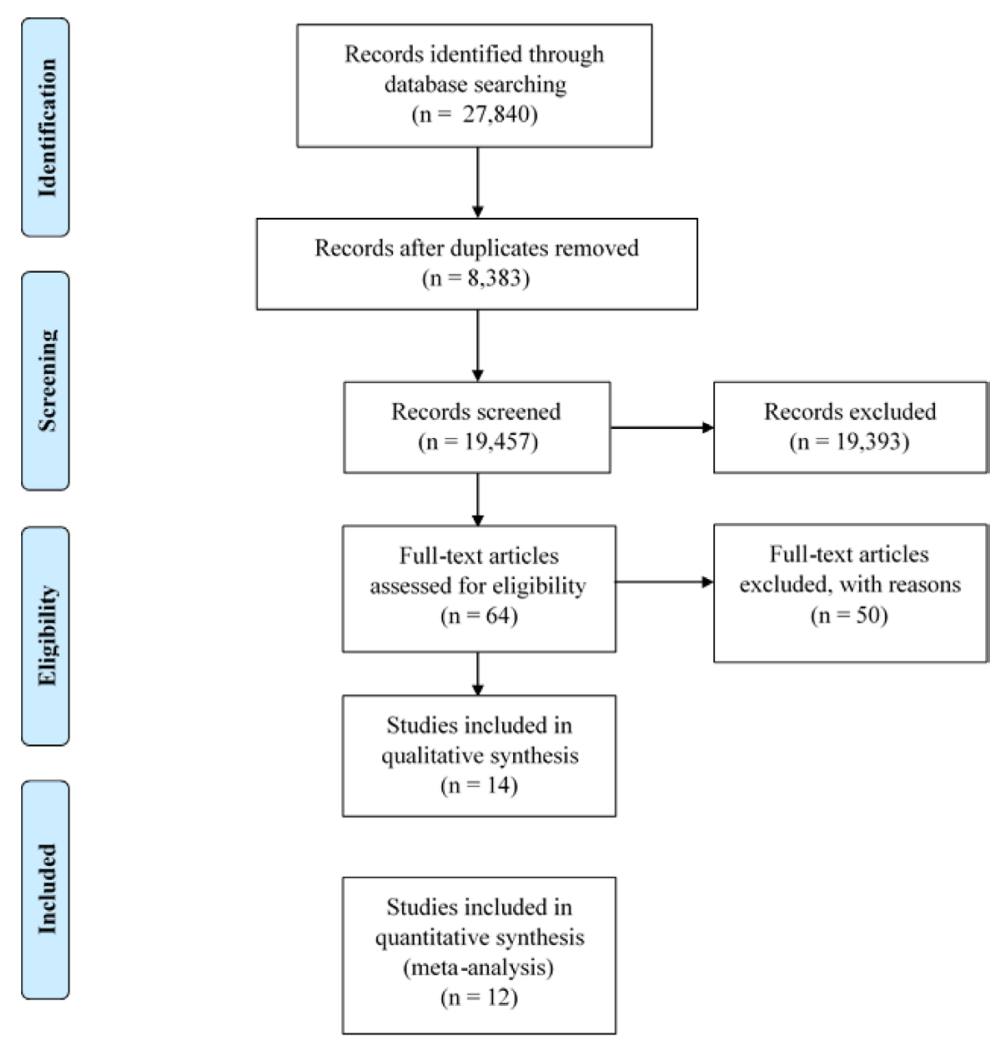

Figure 1 - The flow of studies through the review. n, sample size. 


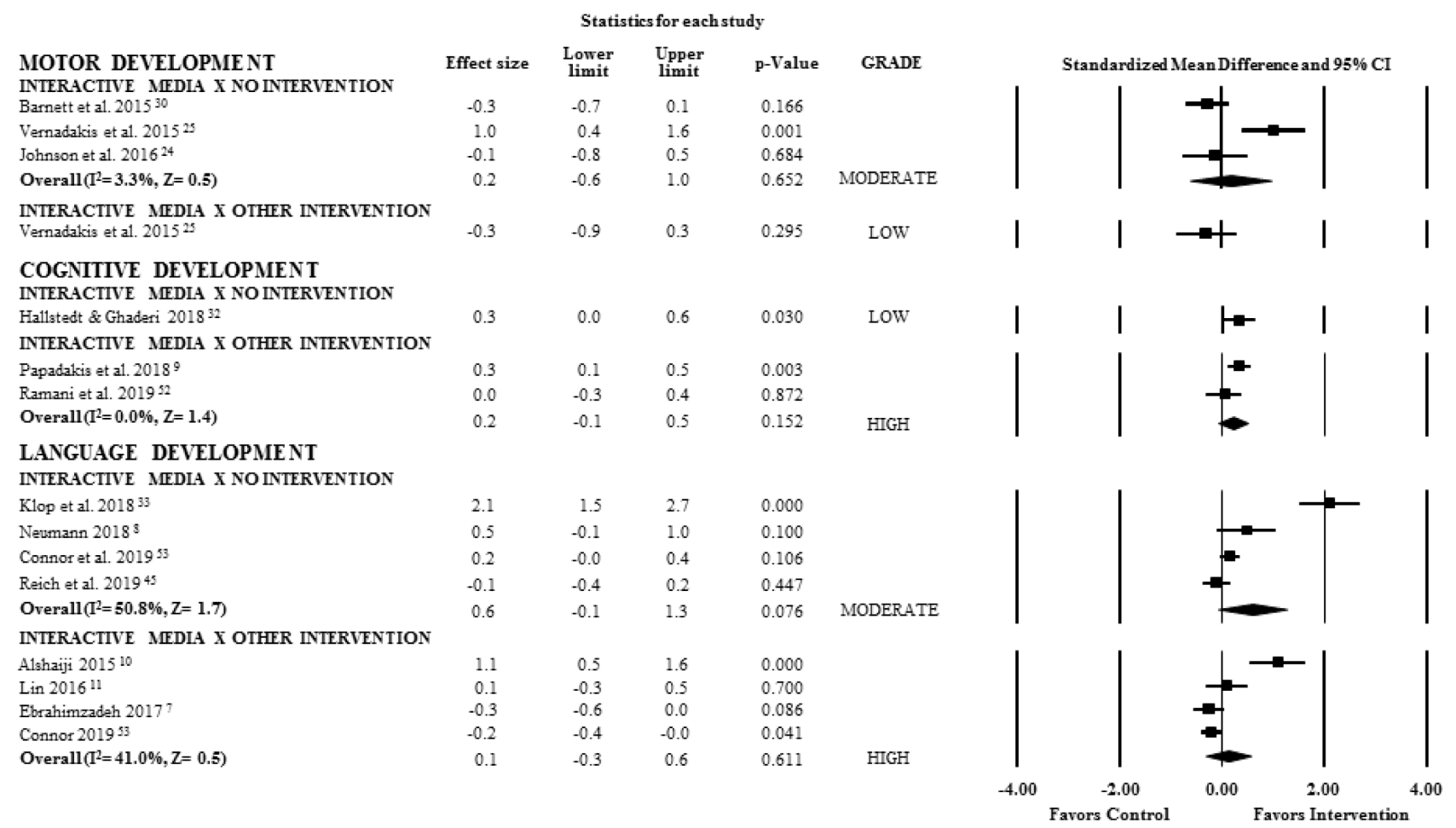

Figure 2 - Pooled results of interactive media compared with no intervention or other intervention on cognitive, language, and motor development at short-term follow-up in healthy children and adolescents. The right side favors intervention. Z, value Z; I2, statistic.

Table 1- Characteristics of the included studies $(n=14)$

\begin{tabular}{|c|c|c|c|c|}
\hline Study & Source & Participants & Intervention & Outcome measures \\
\hline $\begin{array}{l}\text { Alshaiji } \\
\left(2015^{10}\right.\end{array}$ & $\begin{array}{l}\text { Saudi Kids, female, } \\
\text { from an } \\
\text { preschool }\end{array}$ & $\begin{array}{l}\mathrm{n}=60 \\
\text { Age }(y r)=5-6 \\
(\mathrm{SD}=\text { n.a. })\end{array}$ & $\begin{array}{l}\text { Exp }=\text { Play a video game } 3 / \\
\text { wk } 8 \text { wk }(n=30) \\
\text { Exp=OI: Traditional } \\
\text { methods of learning English } \\
(n=30)\end{array}$ & $\begin{array}{l}\text { Cognitive development (English vocabulary- } \\
\text { VVT Posttests range } 0-30 \\
\text { Follow-up }=8 \text { weeks }\end{array}$ \\
\hline $\begin{array}{l}\text { Barnett et al. } \\
(2015)^{30}\end{array}$ & $\begin{array}{l}\text { Students, male and } \\
\text { female, from an } \\
\text { elementary school }\end{array}$ & $\begin{array}{l}\mathrm{n}=59 \\
\text { Age }(y r)=4-8 \\
(\mathrm{SD}=0,95)\end{array}$ & $\begin{array}{l}\operatorname{Exp}=\text { Play an active video } \\
\text { game } 1 / \text { wk } \times 6 \mathrm{wk}(\mathrm{n}=25) \\
\text { Con }=\text { no treatment }(\mathrm{n}=34)\end{array}$ & $\begin{array}{l}\text { Motor development } \\
\text { TGMD-2 OCS } \\
\text { Posttests range } 0-48 \\
\text { Follow-up }=6 \text { weeks }\end{array}$ \\
\hline $\begin{array}{l}\text { Connor et al. } \\
(2019)^{53}\end{array}$ & $\begin{array}{l}\text { Students, male and } \\
\text { female, from an el- } \\
\text { ementary school in } \\
\text { Arizona in the US }\end{array}$ & $\begin{array}{l}\mathrm{n}=603 \\
\text { Age }(y r)=8-10(\mathrm{SD}= \\
\text { n.a. })\end{array}$ & $\begin{array}{l}\text { Exp= Word-Knowledge } \\
\text { e-Book condition- reading } \\
\text { alone (No book club)- 3/wk } \\
\text { x } 3 \text { weeks }(n=200) \\
\text { Exp = OI: Word-Knowl- } \\
\text { edge e-Book condition- } \\
\text { reading alone and meeting } \\
\text { with their book club (book } \\
\text { club) - 3/wk x } 3 \text { weeks } \\
(n=191) \\
\text { Con= no treatment }(n=212)\end{array}$ & $\begin{array}{l}\text { Language development } \\
\text { Word knowledge } \\
\text { Posttests range } 0-15 \\
\text { Follow-up }=3 \text { weeks }\end{array}$ \\
\hline $\begin{array}{l}\text { Ebrahimzadeh } \\
(2017)^{7}\end{array}$ & $\begin{array}{l}\text { Iranian, junior and } \\
\text { senior high school, } \\
\text { male students }\end{array}$ & $\begin{array}{l}\mathrm{n}=190 \\
\text { Age }(y r)=12-18 \\
(\mathrm{SD}=\text { n.a. })\end{array}$ & $\begin{array}{l}\text { Exp } 1=\text { Players' treatment- } \\
1 / \text { wk x } 5 \text { wk }(n=57) \\
\text { Exp 2= OI: Readers' treat- } \\
\text { ment } 1 / \text { wk x } 5 \text { wk }(n=62) \\
\text { Exp 3= OI: Watchers' treat- } \\
\text { ment- } 1 / \text { wk x } 5 \text { wk }(n=71)\end{array}$ & $\begin{array}{l}\text { Language development (vocabulary) } \\
\text { Posttests range } 0-3 \\
\text { Follow-up }=5 \text { weeks }\end{array}$ \\
\hline
\end{tabular}


Second graders spread in 27

Hallstedt \& Ghaderi

$(2018)^{32}$

Johnson et al. $(2016)^{24}$

Kaman \& Ertem $\left(2018^{12}\right.$

Klop et al. $(2018)^{33}$

1st-grade students in the Eastern

Cape.

Adolescents, male and female, 11th

Lin $(2016)^{11}$ graders from a public senior high school in northern Taiwan.

Children, female and male, from six child care

Neumann $(2018)^{8}$ centers in southeast Queensland, Australia.

Children, female and male, from 21 early childhood classes (state or

private) in Greece

$\mathrm{n}=365$

Age $(y r)=5$

al. $(2018)^{9}$

kindergarten children, male and

Ramani et al. $(2019)^{52}$ female, from elementar schools on the east and west coast of the United States

Children, male and

Reich et al. female, from pre(2019) ${ }^{45}$ schools in Southern California (USA)

$\mathrm{n}=200$ Age $(y r)=4,5$ $(\mathrm{SD}=0,45)$

Students in first and second grades, Vernadakis et male and female, al. $(2015)^{25}$

from three public elementary schools in southern Greece

$\mathrm{n}=94$
Age $(y r)=\mathrm{n} . \mathrm{a}$.

$\mathrm{n}=48$

Age $(y r)=2-5$

$(\mathrm{SD}=0,73)$

$(\mathrm{SD}=0,45)$

$\mathrm{n}=143$

Age $(y r)=5,9$

$(\mathrm{SD}=0,40)$

$\mathrm{n}=66$

$0,73)$
Exp 1= Math + Working Memory Training $30 \mathrm{~min} 5 /$ wk x 19,1 wk (n=76)

Exp 2= OI: Math Training

$20 \mathrm{~min} 5 / \mathrm{wk} \times 20,1 \mathrm{wk}(\mathrm{n}=75)$

Exp 3= Placebo $30 \mathrm{~min} 5 / \mathrm{wk}$

$\mathrm{x} 20,2 \mathrm{wk}(\mathrm{n}=78)$

$\mathrm{Con}=$ No intervention $(\mathrm{n}=52)$

$\operatorname{Exp}=$ Play an active educational video game 1/wk x 6 wk $(\mathrm{n}=19)$

Con $=$ no treatment $(\mathrm{n}=17)$

Exp= Read digital texts. 1/

wk $x$ 14wk $(n=15)$

Con $=$ Read the texts in print.

$1 / \mathrm{wk} \times 14 \mathrm{wk}(\mathrm{n}=15)$

$\mathrm{Exp}=\mathrm{E}$-book intervention -

$20 \mathrm{~min} 3 / \mathrm{wk} \times 2 \mathrm{wk}(\mathrm{n}=33)$

Con $=$ No intervention (n

$=32$ )

Exp $=$ mobile group $50 \mathrm{~min}$ $5 /$ wk $(\mathrm{n}=52)$

$\mathrm{Exp}=\mathrm{OI}$ : paper group 50 $\min 5 / \mathrm{wk}(\mathrm{n}=42)$

$\operatorname{Age}(y r)=6-7(\mathrm{SD}=$

Exp= iPad Group $30 \mathrm{~min} /$

wk 9 wk $(n=24)$

Con $=$ no intervention $(\mathrm{n}=$ 24)

Exp $1=$ Computer $(n=134)$

Exp 2= OI: Tablets - educational software was in key areas of early mathematics. $30 \mathrm{~min} \times 14 \mathrm{wk}(\mathrm{n}=122)$

Con $=$ OI: Extra mathematics activities with handsmathematics instruction 30 on $\min \mathrm{x} 14 \mathrm{wk}(\mathrm{n}=109)$

Exp $=$ training games -16 sessions $(\mathrm{n}=93$ )

Exp $=$ OI: Active control $(\mathrm{n}=50)$

Exp $=$ Read an e-Book -1 session $(n=100)$

Exp= OI: read a Print Book1 session $(n=100)$

Exp $=$ Play an active video game $2 /$ wk x 8 wk $(n=22)$

$\mathrm{Exp}=\mathrm{OI}$ : TA intervention for developing the $\mathrm{OC}$
Cognitive development GRID, the test was based on the Automated Working Memory Assessment

Posttests range: an

Follow-up $=6$ and 12 months

Motor development

TGMD3-OCS

Posttests range $0-100$

Follow-up $=6$ weeks

Language development

Number of

Error in Reading

Posttests range: $0-50$

Follow-up: 14 weeks

Language development

Receptive vocabulary knowledge task

Posttests range: $0-15$ points.

Follow-up: 8 weeks

Language development

Reading proficiency tests

Posttests range: $0-45$

Follow-up: 5 weeks condition -16 sessions

skills. $2 /$ wk x 8 wk $(n=22)$

Language development

Clay's Concepts About Print test

Posttests range: 0-10

Follow-up: 9 weeks

Cognitive development TEMA-3: assess mathematical skills

Posttests range: $0-72$

Follow-up: 14 weeks

Cognitive development

Working memory - touch base bw range 0-7

1 month retention

Language development

Posttest book's question- range $0-13$

Motor development

TGMD-2 OCS

Posttests range 0-48

Follow-up $=8$ weeks

Note: $\mathrm{RCT}=$ randomized controlled trial; $\mathrm{MP}=$ myofascial pain $\mathrm{n}=$ sample size $\mathrm{SD}=$ standard deviation $;$ Exp $=\exp$ minerimental group Con $=$ control group; $\mathrm{OI}=$ other intervention. $\mathrm{SKT}=$ standardized knowledge test; $\mathrm{TGMD}=$ Test of Gross Motor Development; OCS: object control skills; TA= Traditional activity VVT: validated vocabulary test TEMA-3= Test of Early Mathematics Ability - Third Edition 
Table 2 - The methodological quality of the included studies using the PEDro scale $(n=14)$

\begin{tabular}{|c|c|c|c|c|c|c|c|c|c|c|c|}
\hline Study & $\begin{array}{l}\text { Random } \\
\text { allocation }\end{array}$ & $\begin{array}{l}\text { Concealed } \\
\text { allocation }\end{array}$ & $\begin{array}{c}\text { Groups } \\
\text { similar at } \\
\text { baseline }\end{array}$ & $\begin{array}{c}\text { Participant } \\
\text { blinding }\end{array}$ & $\begin{array}{l}\text { Therapist } \\
\text { blinding }\end{array}$ & $\begin{array}{l}\text { Assessor } \\
\text { blinding }\end{array}$ & $\begin{array}{l}<15 \% \\
\text { dropouts }\end{array}$ & $\begin{array}{c}\text { Intention-to-treat } \\
\text { analysis }\end{array}$ & $\begin{array}{c}\text { Between-group } \\
\text { difference } \\
\text { reported }\end{array}$ & $\begin{array}{l}\text { Point estimate and } \\
\text { variability reported }\end{array}$ & $\begin{array}{l}\text { Total } \\
\text { (0 to 10) }\end{array}$ \\
\hline $\begin{array}{l}\text { Alshaiji } \\
(2015)^{10}\end{array}$ & $\mathrm{Y}$ & $\mathrm{N}$ & Y & $\mathrm{N}$ & $\mathrm{N}$ & $\mathrm{N}$ & $\mathrm{Y}$ & Y & Y & $\mathrm{Y}$ & 6 \\
\hline $\begin{array}{l}\text { Barnett } \\
(2015)^{30}\end{array}$ & $\mathrm{Y}$ & $\mathrm{N}$ & $\mathrm{Y}$ & $\mathrm{N}$ & $\mathrm{N}$ & $\mathrm{N}$ & $\mathrm{N}$ & $\mathrm{N}$ & $\mathrm{Y}$ & $\mathrm{Y}$ & 4 \\
\hline $\begin{array}{l}\text { Connor et al. } \\
(2019)^{53}\end{array}$ & $\mathrm{Y}$ & $\mathrm{N}$ & Y & $\mathrm{N}$ & $\mathrm{N}$ & $\mathrm{Y}$ & Y & $\mathrm{N}$ & Y & Y & 6 \\
\hline $\begin{array}{l}\text { Ebrahimzadeh } \\
(2017)^{7}\end{array}$ & $\mathrm{Y}$ & $\mathrm{N}$ & $\mathrm{Y}$ & $\mathrm{N}$ & $\mathrm{N}$ & $\mathrm{N}$ & $\mathrm{Y}$ & $\mathrm{N}$ & $\mathrm{Y}$ & $\mathrm{Y}$ & 5 \\
\hline $\begin{array}{l}\text { Hallstedt } \\
\& \text { Ghaderi } \\
(2018)^{32}\end{array}$ & $\mathrm{Y}$ & Y & $\mathrm{Y}$ & $\mathrm{N}$ & $\mathrm{N}$ & $\mathrm{N}$ & Y & $\mathrm{N}$ & Y & $\mathrm{Y}$ & 6 \\
\hline $\begin{array}{l}\text { Johnson et al. } \\
(2016)^{24}\end{array}$ & $\mathrm{Y}$ & $\mathrm{Y}$ & $\mathrm{Y}$ & $\mathrm{N}$ & $\mathrm{N}$ & $\mathrm{Y}$ & $\mathrm{Y}$ & $\mathrm{N}$ & $\mathrm{Y}$ & $\mathrm{Y}$ & 7 \\
\hline $\begin{array}{l}\text { Kaman \& Er- } \\
\text { tem }(2018)^{12}\end{array}$ & $\mathrm{Y}$ & Y & Y & $\mathrm{N}$ & $\mathrm{N}$ & $\mathrm{N}$ & Y & Y & Y & $\mathrm{Y}$ & 7 \\
\hline $\begin{array}{l}\text { Klop et al. } \\
(2018)^{33}\end{array}$ & $\mathrm{Y}$ & $\mathrm{N}$ & $\mathrm{Y}$ & $\mathrm{N}$ & $\mathrm{N}$ & $\mathrm{N}$ & $\mathrm{Y}$ & $\mathrm{Y}$ & Y & Y & 6 \\
\hline $\operatorname{Lin}(2016)^{11}$ & Y & Y & Y & $\mathrm{N}$ & $\mathrm{N}$ & $\mathrm{N}$ & $\mathrm{N}$ & $\mathrm{N}$ & Y & Y & 5 \\
\hline $\begin{array}{l}\text { Neuman } \\
(2018)^{8}\end{array}$ & Y & Y & $\mathrm{Y}$ & $\mathrm{N}$ & $\mathrm{N}$ & $\mathrm{N}$ & Y & Y & Y & Y & 7 \\
\hline $\begin{array}{l}\text { Papadaki et } \\
\text { al. }(2018)^{9}\end{array}$ & $\mathrm{Y}$ & Y & Y & $\mathrm{N}$ & $\mathrm{N}$ & $\mathrm{N}$ & Y & Y & Y & Y & 7 \\
\hline $\begin{array}{l}\text { Ramani et al. } \\
\text { (2019) }{ }^{52}\end{array}$ & $\mathrm{Y}$ & $\mathrm{N}$ & $\mathrm{Y}$ & $\mathrm{N}$ & $\mathrm{N}$ & $\mathrm{Y}$ & Y & $\mathrm{Y}$ & $\mathrm{Y}$ & $\mathrm{Y}$ & 7 \\
\hline $\begin{array}{l}\text { Reich et al. } \\
(2019)^{45}\end{array}$ & $\mathrm{Y}$ & $\mathrm{N}$ & Y & $\mathrm{N}$ & $\mathrm{N}$ & $\mathrm{N}$ & $\mathrm{Y}$ & $\mathrm{N}$ & $\mathrm{Y}$ & $\mathrm{Y}$ & 5 \\
\hline $\begin{array}{l}\text { Vernadakis et } \\
\text { al. }(2015)^{25}\end{array}$ & $\mathrm{Y}$ & $\mathrm{Y}$ & $\mathrm{Y}$ & $\mathrm{N}$ & $\mathrm{N}$ & $\mathrm{N}$ & $\mathrm{Y}$ & $\mathrm{Y}$ & $\mathrm{Y}$ & $\mathrm{Y}$ & 7 \\
\hline
\end{tabular}

Note: $\mathrm{Y}=\mathrm{Yes}, \mathrm{N}=\mathrm{No}$

\section{Discussion}

This systematic review of randomized controlled trials has investigated the effects of interactive media on the cognitive, language, and motor development of children and adolescents, in comparison with other interventions or no interventions. Our results suggest that the use of interactive media has no effect on the motor, cognitive, and language development compared with other interventions. However, high-quality evidence was found that interactive media is not superior to other interventions for cognitive and language development outcomes. When compared to the control group the use of interactive media has only a small effect on cognitive development and estimates showed a moderate level of evidence of little to no effect of interactive media use on motor and language development.
Regarding motor development, no effect was identified for studies comparing the use of interactive media with the control group $^{24,25,30}$ or with traditional object control activities ${ }^{25}$. The quality of evidence in this regard was also low to moderate, lacking in accuracy and consistency. The RCTs do not reveal significant results when evaluating the effect of interactive media on object control (gross motor skill). The authors justify such findings with an explanation that the video game used is not sensitive to the typical developing population, generating a certain ceiling effect to the baseline data ${ }^{24,30}$. The intervention time and duration are not sufficient to generate significant results, and the media used (video game - Nintendo Wii) may not have been adequate, as it needs to be controlled by the hands, which would limit the execution of certain movements, thus impairing the player ${ }^{24,30}$. In addition, it is extremely important for motor development 
that children and adolescents have physical experiences with different spaces and environments, which is limited when using the researched interactive media ${ }^{55}$. No randomized controlled trials with fine motor skills as the outcome were found in the literature. Cross-sectional and comparative studies suggest a relation between the use of interactive media and this skills ${ }^{26,56,57}$.

Our results suggest that the use of interactive media has only a small effect on cognitive development compared with the control group ${ }^{32}(\mathrm{p}=.030)$ and with other intervention groups ${ }^{9}:$ (1) classroom activities similar to interactive media activities; and (2), mathematics activities on the computer $(\mathrm{p}=.003)$, both with a low level of evidence for the short-term interventions. Short- or medium-term effects were not found in the literature. However, preliminary, uncontrolled studies suggest that children can learn using interactive media ${ }^{58}$ and have the ability to transfer skills learned on touchscreen devices to physical objects ${ }^{59,60}$, further suggesting that interactive media can serve as complementary material to classroom learning $8,9,58$. A recently developed index shows that the quality of use of interactive media, with regard to parental or guardian supervision over the use and limitation of time, and content and purpose of use, can positively influence child development ${ }^{61}$. However, larger sample size and better methodological quality are needed to confirm these findings and strengthen the level of evidence. The results of this review point to the uncertainty of the effects of interactive media on children, which should be considered by parents, and health and education professionals.

With regard to language development, four trials were studied comparing interactive media to the control group $p^{8,33,45,53}$. Tree studies compared interactive e-book use with the control group $^{33,45,53}$ and one compared tablet use ${ }^{8}$ and no intervention. No significant effects $(p=.07)$ of the media were observed. In addition, the level of evidence was low due to inconsistency $\left(\mathrm{I}^{2}=50,8\right)$. The studies evaluated children from 2 to 10 years old and the time of intervention between them was also varied, with measurement of the immediate effects up to 9 weeks of follow-up, which may explain the heterogeneity found.

When comparing tablet and video game use with traditional learning and observation methods ${ }^{7,10,11,53}$, we found no effect of using interactive media in learning a new vocabulary and reading proficiency. Interactive media have various distinctive features such as individualized interfaces, real-time access to information, context-sensitivity, instant communication, and feedback ${ }^{62}$. These features may be able to increase the effects of learning. However, it is noteworthy that the features of interactive media are not enough conditions for positive learning effects. The absence of the effects of media in our study illustrated this fact.

In this study, we observed that the high-quality evidence that supports the effect of the use of interactive media on the development of language, cognitive, and motor skills. Thus, new RCTs are needed to determine the effectiveness of this type of intervention.

The current study has major strengths. First, the subject of this review could not be more current, since the use of interactive media is a global phenomenon that grows exponentially, especially in the current context of the Covid pandemic $19^{63}$. Second, this systematic review and meta-analysis were performed in strict accession to the COCHRANE recommendations and PRISMA guidelines. Third, by thorough literature search through multiple databases, we captured all the relevant articles to date, especially including recently published studies. Fourth, we used strict inclusion and exclusion criteria and conducted extensive data collection to avoid the omission of important information. Overall, our approach aimed to provide the most comprehensive data possible for the effects of interactive media on children and adolescent development, despite limitations in the included studies or our methodology. Firstly, our results indicated a high level of statistical heterogeneity $\left(\mathrm{I}^{2}>50 \%\right)$ for the effect estimate of interactive media compared to no intervention on the language development outcome. It is likely that this heterogeneity result from clinical heterogeneity given the complexity of the interventions implemented in the included trials. To partially overcome this issue, we pooled data using the random-effects and the quality of evidence for this estimate was downgraded from high to moderate due to imprecision. Secondly, our systematic review included few trials and we were underpowered to investigate publication bias. As a rule of thumb, tests for funnel plot asymmetry should be used only when there are at least 10 studies included in the meta-analysis ${ }^{47}$. Thirdly, the participants consisted of a broad range of children with typical development of different ages and ethnicities. Thus, they were not a homogeneous group of participants, and interactive media may have different effects for different conditions. However, our choice for this age range came from recent studies showing that the development occurs up to the end of the adolescence $e^{5,20}$.

\section{Conclusion}

The results of this systematic review do not support claims about the advantages or disadvantages of interactive media in child development. However, high-quality evidence was found that interactive media is not superior to other interventions for cognitive and language development outcomes, and quality of moderate evidence that it is no better than not to receive intervention for motor and language development.

\section{References}

1. Radesky JS, Dimitri A. Christakis DA. Increased Screen Time: implications for early childhood development and behavior. Pediatr Clin N Am. 2016;63:827-39.

2. Bernard JY, Padmapriya N, Chen B, Cai S, Tan KH, Yap F, et al. Predictors of screen viewing time in young Singaporean children: the GUSTO cohort. Int J Behav Nutr Phys Act. 2017;14(1):112.

3. Piñeiro ES, González CR. Repercusión de la interactividad y los nuevos medios de comunicación en los procesos educativos. Investigación y Postgrado. 2006;21(1):187-209.

4. Calder N. Apps: Appropriate, Applicable, and Appealing? 2014. In: Digital Games and Mathematics Learning: Potential, Promises, and Pitfalls [Internet]. Springer; 233-50.

5. Crone EA, Konijn EA. Media use and brain development during adolescence. Nat Commun. 2018;9(1):588. 
6. Wood E, Petkovski M, De Pasquale D, Gottardo A, Evans MA, Savage RS. Parent Scaffolding of Young Children When Engaged with Mobile Technology. Front Psychol. 2016;7:690.

7. Ebrahimzadeh M. Readers, Players, and Watchers: EFL Students' Vocabulary Acquisition through Digital Video Games. Canadian Center of Science and Education [Internet]. 2017; 10: 1-18.

8. Neumann MM. Using tablets and apps to enhance emergent literacy skills in young children. Early Childhood Research Quarterly [Internet]. 2018; 42: 239-46.

9. Papadakis S, Michail Kalogiannakis M, Zaranis, N. The effectiveness of computer and tablet assisted intervention in early childhood students' understanding of numbers. An empirical study conducted in Greece. Educ Inf Technol [Internet]. 2018; 23:1849-71.

10. Alshaiji AO. Video games promote Saudi children's English vocabulary retention. Educação [Internet]. 2015; 136:123-32.

11. Lin C-C. Learning English with electronic textbooks on tablet PCs. Interactive Learning Environments [Internet]. 2016; (1744-5191).

12. Kaman S, Ertem IS. The Effect of Digital Texts on Primary Students' Comprehension, Fluency, and Attitude. Eurasian Journal of Educational Research [Internet]. 2018; 76:147-64.

13. Piotrowski JT, Krcmar M. Reading with hotspots: Young children's responses to touch screen stories. Computers in Human Behavior [Internet]. 2017; 70(0747-5632):328-34.

14. Merchant G. Keep taking the tablets: iPads, story apps, and early literacy. Australian Journal of Language and Literacy. 2015;38:3-11.

15. Brindova D, Pavelka J, Ševčikova A, Žežula I, van Dijk JP, Reijneveld SA, et al. How parents can affect excessive spending of time on screen-based activities. BMC Public Health. 2014; $14: 1261$.

16. Wu CS, Fowler C, Lam WY, Wong HT, Wong CH, Yuen Loke A. Parenting approaches and digital technology use of preschool-age children in a Chinese community. Ital J Pediatr. 2014;40:44.

17. Media Coca. Media and Young Minds. Pediatrics. 2016;138(5).

18. Guedes SDC, Morais RLS, Santos LR, Leite HR, Nobre JNP, Santos JN. Children's use of interactive media in early childhood - an epidemiological study. Rev Paul Pediatr. 2020;38:e2018165.

19. Hadders-Algra M. Interactive media use and early childhood development. J Pediatr (Rio J). 2019.

20. Christakis DA, Ramirez JSB, Ferguson SM, Ravinder S, Ramirez JM. How early media exposure may affect cognitive function: A review of results from observations in humans and experiments in mice. Proc Natl Acad Sci U S A. 2018;115(40):9851-8.

21. Felix E, Silva V, Caetano M, Ribeiro MVV, Fidalgo TM, Rosa Neto F, et al. Excessive Screen Media Use in Preschoolers Is Associated with Poor Motor Skills. Cyberpsychol Behav Soc Netw. 2020;23(6):418-25.

22. Hardy LL, Ding D, Peralta LR, Mihrshahi S, Merom D. Association Between Sitting, Screen Time, Fitness Domains, and Fundamental Motor Skills in Children Aged 5-16 Years: Cross-Sectional Population Study. J Phys Act Health. 2018;15(12):933-40.

23. Webster EK, Martin CK, Staiano AE. Fundamental motor skills, screen-time, and physical activity in preschoolers. J Sport Health Sci. 2019;8(2):114-21.
24. Johnson TM, Ridgers ND, Hulteen RM, Mellecker RM, Barnett, M L. Does playing a sports active video game improve young children's ball skill competence? Journal of Science and Medicine in Sport [Internet]. 2016; 19:432-6.

25. Vernadakis N, Papastergiou M, Zetou E, Antoniou P. The impact of an exergame-based intervention on children's fundamental motor skills. Computers \& Education [Internet]. 2015; 83:90-102.

26. Souto PHS, Santos JN, Leite HR, Hadders-Algra M, Guedes SC, Nobre JNP, et al. Tablet Use in Young Children is Associated with Advanced Fine Motor Skills. J Mot Behav. 2019:1-8.

27. Axford C, Joosten AV, Harris C. iPad applications that required a range of motor skills promoted motor coordination in children commencing primary school. Aust Occup Ther J. 2018;65(2):146-55.

28. Wheaton N, Millar L, Allender S, Nichols M. The stability of weight status through the early to middle childhood years in Australia: a longitudinal study. BMJ Open. 2015;5(4):e006963.

29. Poitras VJ, Gray CE, Janssen X, Aubert S, Carson V, Faulkner G, et al. Systematic review of the relationships between sedentary behaviour and health indicators in the early years (0-4 years). BMC Public Health. 2017;17(Suppl 5):868.

30. Barnett LM, Ridgers ND, Reynolds J, Hanna L, Salmon J. Playing Active Video Games may not develop movement skills: An intervention trial. Preventive Medicine Reports [Internet]. 2015; 2:673-8.

31. Moon JH, Cho SY, Lim SM, Roh JH, Koh MS, Kim YJ, et al. Smart device usage in early childhood is differentially associated with fine motor and language development. Acta Paediatr. 2019;108(5):903-10.

32. Hallstedt H, Ghaderi Tka. Short and Long-Term Effects of a Mathematics Tablet Intervention for Low Performing Second Graders. Journal of Educational Psychology [Internet]. 2018; 110:1127-48.

33. Klop D, Marais L, Msindwana A, De Wet F. Learning new words from an interactive electronic storybook intervention. S Afr J Commun Disord. 2018;65(1):e1-e8.

34. Labrensz J, Ayebo A. Effects of Personal Learning Devices and Their Usageson Student Learning and Engagement. J1 of Computers in Mathematics and Science Teaching [Internet]. 2018; 37:193-216.

35. Radesky JS, Schumacher J, Zuckerman B. Mobile and interactive media use by young children: the good, the bad, and the unknown. Pediatrics. 2015;135(1):1-3.

36. Cespedes EM, Gillman MW, Kleinman K, Rifas-Shiman SL, Redline S, Taveras EM. Television viewing, bedroom television, and sleep duration from infancy to mid-childhood. Pediatrics. 2014;133(5):e1163-71.

37. Dempsey AG, Barton AK, Duncan AF. Differences in Performance on Developmental Tasks in Young Children Across Digital and Paper-Based Modalities: A Feasibility Trial. J Dev Behav Pediatr. 2018;39(9):726-35.

38. Longo E, de Campos AC, Palisano RJ. Let's make pediatric physical therapy a true evidence-based field! Can we count on you? Braz J Phys Ther. 2019;23(3):187-8.

39. Nacional C. ECA: Estatuto da Criança e do Adolescente,Lei $\mathrm{n}^{\circ}$ 8.069, de 13 de 1990. In: Ministério da Mulher DFEDDH, editor. Brasília 2019. 
40. Dundar H, Akcayir M. Tablet vs. Paper: The Effect on Learners' Reading Performance. International Electronic Journal of Elementary Education [Internet]. 2012; 4(1307-9298):[441-50 pp.]. Available from: https://eric.ed.gov/?id=EJ1068592.

41. Howie EK, Campbell AC, Straker LM. An active video game intervention does not improve physical activity and sedentary time of children at-risk for developmental coordination disorder: a crossover randomized trial. Child Care Health Dev. 2016;42(2):253-60.

42. Hsieh RL, Lee WC, Lin JH. The Impact of Short-Term Video Games on Performance among Children with Developmental Delays: A Randomized Controlled Trial. PLoS One. 2016;11(3):e0149714.

43. Sun H, Gao Y. Impact of an active educational video game on children's motivation, science knowledge, and physical activity. J Sport Health Sci. 2016;5(2):239-45.

44. Master A, Cheryan S, Moscatelli A, Meltzoff AN. Programming experience promotes higher STEM motivation among first-grade girls. J Exp Child Psychol. 2017;160:92-106.

45. Reich SM, Yau JC, Xu Y, Muskat T, Uvalle J, Cannata D. Digital or Print? A Comparison of Preschoolers' Comprehension, Vocabulary, and Engagement From a Print Book and an e-Book. AERA Open. 2019;5:1-16.

46. Maher CG, Sherrington C, Herbert RD, Moseley AM, Elkins M. Reliability of the PEDro scale for rating quality of randomized controlled trials. Phys Ther. 2003;83(8):713-21.

47. Higgins JP, Green S. Cochrane Handbook for Systematic Reviews of Interventions Version 5.1.0. . CochraneBook Series [Internet]. 2011. Available from: https://pdfs.semanticscholar.org/4b43/91c08c45ebfcd046a53106c97ca09fcdf9fa.pdf.

48. DerSimonian R, Laird N. Meta-analysis in clinical trials. Controlled Clinical Trials [Internet]. 1986; 7:177-88.

49. Balshem H, Helfand M, Schünemann HJ, Oxman AD, Kunz R, Brozek J, et al. GRADE guidelines: 3. Rating the quality of evidence. J Clin Epidemiol. 2011;64(4):401-6.

50. Mueller PS, Montori VM, Bassler D, Koenig BA, Guyatt GH. Ethical issues in stopping randomized trials early because of apparent benefit. Ann Intern Med. 2007;146(12):878-81.

51. Ioannidis JP, Trikalinos TA. The appropriateness of asymmetry tests for publication bias in meta-analyses: a large survey. CMAJ. 2007;176(8):1091-6.

52. Ramani GB, Daubert EN, Lin GC, Kamarsu S, Wodzinski A, Jaeggi SM. Racing dragons and remembering aliens: Benefits of playing number and working memory games on kindergartners' numerical knowledge. Dev Sci. 2020;23(4):e12908.

53. Connor CM, Day SL, Zargar E, Wood TS, Taylor KS, Jones MR, et al. Building Word Knowledge, Learning Strategies, and Metacognition with the Word-Knowledge E-Book. Comput Educ. 2019;128:284-311.

54. Centers for Disease Control and Prevention. Learn the signs. Act early: CDC's Developmental Milestones 2019 [Available from https://www.cdc.gov/ncbddd/actearly/milestones/.
55. Straker L, Pollock C. Optimizing the interaction of children with information and communication technologies. Ergonomics. 2005;48(5):506-21.

56. Price S, Jewitt C, Crescenzi L. The role of iPads in preschool children's mark-making development2015; 87:131-41. Available from: https://www.sciencedirect.com/science/article/ pii/S0360131515001025.

57. Bedford R, Saez de Urabain IR, Cheung CH, Karmiloff-Smith A, Smith TJ. Toddlers' Fine Motor Milestone Achievement Is Associated with Early Touchscreen Scrolling. Front Psychol. 2016;7:1108.

58. Kwok K, Ghrear S, Li V, Haddock T, Coleman P, Birch SA. Children Can Learn New Facts Equally Well From Interactive Media Versus Face to Face Instruction. Front Psychol. 2016;7:1603.

59. Huber B, Tarasuik J, Antoniou MN, Garrett C, Bowe SJ, Swinburne JK, et al. Young children's transfer of learning from a touchscreen device. Comput Human Behav [Internet]. 2016; 56:56-64. Available from: https://www.sciencedirect.com/science/ article/pii/S0747563215302259.

60. Galetzka C. Commentary: Mobile and Interactive Media Use by Young Children: The Good, the Bad, and the Unknown. Front Psychol. 2017;8:461.

61. Nobre JNP, Vinolas Prat B, Santos JN, Santos LR, Pereira L, Guedes SDC, et al. Quality of interactive media use in early childhood and child development: a multicriteria analysis. J Pediatr (Rio J). 2019.

62. Reich SM, Yau JC, Warschauer M. Tablet-Based eBooks for Young Children: What Does the Research Say? J Dev Behav Pediatr. 2016;37(7):585-91.

63. Xiang M, Zhang Z, Kuwahara K. Impact of COVID-19 pandemic on children and adolescents' lifestyle behavior larger than expected. Prog Cardiovasc Dis. 2020.

\section{Corresponding author}

Sabrina da Conceição Guedes

Universidade Federal dos Vales do Jequitinhonha e Mucuri, Programa de Pós-graduação em Reabilitação e Desempenho Funcional, Diamantina, MG, Brasil. Campus JK, MGT 367, Km 583, no 5000 Alto da Jacuba, Diamantina - MG, 39100-000 Email: sabrinaguedes.ufvjm@gmail.com

Manuscript received on May 20, 2020

Manuscript accepted on October 1, 2020

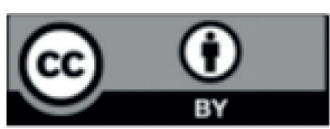

Motriz. The Journal of Physical Education. UNESP. Rio Claro, SP, Brazil - eISSN: 1980-6574 - under a license Creative Commons - Version 4.0 